\title{
Electroclinical characteristics of seizures arising from the precuneus based on stereoelectroencephalography (SEEG)
}

\author{
Yanfeng Yang ${ }^{1,2}$, Haixiang Wang ${ }^{3}$, Wenjing Zhou ${ }^{3}$, Tianyi Qian ${ }^{4}$, Wei Sun ${ }^{1 *}$ and Guoguang Zhao ${ }^{2 *}$
}

\begin{abstract}
Background: Seizures arising from the precuneus are rare, and few studies have aimed at characterizing the clinical presentation of such seizures within the anatomic context of the frontoparietal circuits. We aimed to characterize the electrophysiological properties and clinical features of seizures arising from the precuneus based on data from stereoelectroencephalography (SEEG).

Methods: The present retrospective study included 10 patients with medically intractable epilepsy, all of whom were diagnosed with precuneal epilepsy via stereoelectroencephalography (SEEG) at Yuquan Hospital and Xuan Wu Hospital between 2014 and 2016. Clinical semiology, scalp electroencephalography (EEG) findings, magnetic resonance images (MRI), and positron emission tomography (PET) images were analyzed during phase I preoperative evaluations. Following electrode implantation, the semiological sequence, ictal SEEG evolution, and anatomy of the relevant brain structures were analyzed for each seizure.

Results: Seven of ten patients reported auras, including body image disturbance (2/7), vestibular responses (2/7), somatosensory auras (1/7), visual auras (1/7), and non-specific auras (1/7). Primary motor manifestations included bilateral asymmetric tonic seizures (BATS) (7/10) and hypermotor seizures (HMS) (3/10). In one patient, epileptiform discharge on interictal EEG occurred ipsilateral to the side of the epileptogenic zone (EZ). Discharge was non-lateralized in the remaining nine patients. In six patients, interictal EEG signals were primarily localized in the temporal-parietaloccipital area. In two patients, ictal onset occurred ipsilateral to the EZ, which was mainly located in the temporalparietal-occipital area. Two patterns of seizure spread were observed. The first pattern was characterized by BATS activity with ictal spread to the supplementary motor area (SMA), paracentral lobule (PCL), precentral gyrus (PrCG), or postcentral gyrus (PoCG). The second pattern was characterized by HMS activity with ictal spread to middle cingulate cortex (MCC) and posterior cingulate cortex (PCC).
\end{abstract}

Conclusion: Aura type (e.g., body image disturbance and vestibular response), BATS, and HMS are the main indicators of precuneal epilepsy. Scalp EEG is of little use when attempting to localize precuneal seizures. Our findings indicate that the clinical characteristics of precuneal epilepsy vary among patients, and that the final electro-clinical phenotype depends on the pattern of seizure spread.

Keywords: Precuneal epilepsy, SEEG, Electroclinical characteristics, Anatomical-electrical-clinical correlations

\footnotetext{
*Correspondence: bmusunnyw@163.com; ggzhao@vip.sina.com

'Department of Neurology, Xuan Wu Hospital, Capital Medical University, No

45, Changchun Street, Xicheng District, Beijing 100053, China

${ }^{2}$ Department of Neurosurgery, Xuan Wu Hospital, Capital Medical University,

No 45, Changchun Street, Xicheng District, Beijing 100053, China

Full list of author information is available at the end of the article
}

(c) The Author(s). 2018 Open Access This article is distributed under the terms of the Creative Commons Attribution 4.0 International License (http://creativecommons.org/licenses/by/4.0/), which permits unrestricted use, distribution, and reproduction in any medium, provided you give appropriate credit to the original author(s) and the source, provide a link to the Creative Commons license, and indicate if changes were made. The Creative Commons Public Domain Dedication waiver (http://creativecommons.org/publicdomain/zero/1.0/) applies to the data made available in this article, unless otherwise stated. 


\section{Background}

The precuneus is a discrete area located in the posterior region of the medial parietal cortex, neighbored anteriorly by the marginal branch of the cingulate cortex, posteriorly by the parietal-occipital fissure, and inferiorly by the subparietal sulcus [1]. Anatomical and connectivity studies have indicated that the precuneus belongs to a widespread network of cortical and subcortical structures [2]. Primary connections of the precuneus include the posterior cingulate and retrosplenial cortices, other regions of the parietal cortex, the frontal cortex, and the temporal-parietal-occipital area [1]. Among these connections, we focus on the frontoparietal circuits, as they are regarded as the main elements of the cortical motor system [3]. Each motor area receives afferents from a specific set of parietal territories. Studies have shown that area 5ci [4], which is in the anterior medial region of the precuneus, is essentially the secondary somatosensory area due to its close association with the supplementary motor area (SMA), and that areas $5 \mathrm{~L}$ and $5 \mathrm{M}$ are connected to the superior parietal lobule (SPL), medial primary somatosensory area (SI), and motor cortex. The central region of the precuneus exhibits overlap with the mesial 7A and is connected to the dorsolateral and dorsomedial prefrontal cortices $[5,6]$.

Seizures arising from the precuneus are rare, and few studies have aimed to characterize the clinical presentation of such seizures within the anatomic context of the frontoparietal circuits. Previous studies are limited in that their analyses focused on parietal lobe epilepsy as a general entity [7]. These studies showed that an important feature of parietal lobe epilepsy is the polymorphism of ictal manifestation [8]. Parietal lobe epilepsy is usually associated with various auras, including somatosensory impairments; disturbances of body image; vertiginous sensations; and visual, auditory, or aphasic auras $[9,10]$. Focal motor clonic activity, tonic posturing, and oral-gestural automatisms occur in 57,28 , and $17 \%$ of patients, respectively [11]. More recent studies have investigated seizures arising from subregions of the parietal lobe, including the precuneus. Seizures arising from the precuneus are more frequently associated with body movement sensations, visual auras, eye movements, vestibular manifestations, asymmetric tonic posturing, and hypermotor activity [1]. Precuneal epilepsy is difficult to differentiate from other types of epilepsy-particularly frontal lobe epilepsy-because seizure onset occurs at an anatomically deep and semiologically silent area [12]. As such seizures may spread to the frontal cortex, misinterpretation of the clinical manifestations can lead to incorrect localization. False localization has been reported in up to $16 \%$ of cases [13]. Hence, it is important to improve our understanding of the clinical and neurophysiological features of precuneal epilepsy to improve pre-operative evaluation and surgical strategies.
Stereoelectroencephalography (SEEG) offers distinct advantages over conventional noninvasive approaches, which may be insufficient due to the deep origin of precuneal epilepsy. First introduced by Talairach and Bancaud in the early 1960's [14], SEEG is an invasive approach that can be used to reliably identify deeply buried anatomic structures, allowing one to construct a dynamic, three-dimensional (3D) spatiotemporal picture of epileptic activity [15]. Indeed, previous studies have utilized SEEG to precisely investigate the electrical activity of different brain structures involved in seizure generation and propagation $[10,16]$.

In focal epilepsy, the symptoms are determined by the dynamic evolution of epileptic discharge from the initial seizure onset zone to the adjacent/distant cortical or subcortical areas. Therefore, characterizing the temporospatial evolution of seizure propagation and symptoms is crucial for improving our understanding of different clinical phenotypes $[17,18]$. In the present study, we investigated the electroclinical characteristics of epilepsy originating from the precuneus, as well as the correlation between clinical phenotypes and the ictal pattern of seizure propagation.

\section{Methods \\ Participants}

The present retrospective study included 10 patients (9 men, 1 woman) with medically intractable epilepsy, all of whom underwent evaluation for surgical treatment at Yuquan Hospital and Xuan Wu Hospital between 2014 and 2016. The strategy for SEEG electrode implantation was decided upon during a multidisciplinary patient management conference at the Epilepsy Center. SEEG electrodes were implanted following comprehensive evaluation of each patient, which included a detailed history, video-EEG recording, MRI, PET, and other noninvasive localization methods. Patients with precuneal epilepsy were selected based on the following criteria: (a) SEEG-confirmed seizure onset from the precuneus; (b) extent of surgical excision limited or mostly limited within the precuneus; (c) post-operative follow-up at least every 6 months and ILAE Class 1-2 [19]; (d) no evidence of progressive brain disorders or systemic diseases. All included patients and caregivers provided written informed consent to participate and for publication. Patients in whom multiple epileptogenic zones or possible epileptogenic lesions were identified (e.g., tuberous sclerosis, multiple cavernous hemangioma) and those in whom independent epileptogenic cortical areas beyond the precuneus were confirmed using SEEG were excluded.

We began with 13 cases of electrodes embedded in the precuneus, but two of them were excluded due to diffuse electrodecremental events observed in the SEEG and 
uncertain seizure onset zones. An additional case was excluded due to bilateral epileptic foci and rejection of surgical treatment by the patient and family. Finally, we enrolled 10 patients. The clinical characteristics of the included patients are shown in Table 1. The mean age at seizure onset was $6.15 \pm 6.2$ years. The mean age at consultation was $13.6 \pm 5.6$ years. Our analyses focused on clinical semiology, as well as scalp EEG/SEEG findings.

\section{Analysis of long-term scalp EEG monitoring and clinical semiology}

Clinical characteristics and the results of scalp EEG monitoring are shown in Table 2. Prolonged EEG data were acquired via video-EEG monitoring (Nihon Kohdon, Japan or Bio-logic, USA). All patients underwent at least three typical seizures while awake and during sleep. The recording parameters were as follows: sampling rate $=1024 \mathrm{~Hz}$, low filter setting $=0.16 \mathrm{~Hz}$, high filter setting $=70 \mathrm{~Hz}(\mathrm{Ni}-$ hon Kohdon, Japan) or sampling rate $=256 \mathrm{~Hz}$, low filter setting $=0.16 \mathrm{~Hz}$, and high filter setting $=70 \mathrm{~Hz}$ (Bio-logic, USA). Each EEG sample was analyzed and classified according to the following criteria: (a) lateralization: (i) left, (ii) right, or (iii) not applicable (NA, when bilateral, generalized, or non-lateralized); (b) site: (i) frontal, (ii) temporal, (iii) parietal, (iv) occipital, (v) vertex, or (vi) not applicable (NA, when generalized or non-localized).

Three independent clinicians utilized Lüders' semiological seizure classification to evaluate ictal semiology and determine the semiological evolution sequence $[18,20]$. For patients who experienced auras, aura information was derived from their previous medical history if disturbance of consciousness or postictal amnesia occurred during monitoring.

\section{Implantation of electrodes and analysis of anatomic- electrical-clinical correlations based on SEEG findings}

A T1-weighted MRI scan and magnetic resonance angiography data were integrated to construct three-dimensional images using Neurotech stereotactic software (Neurotech, China). SEEG electrode implantation was based on a preimplantation hypothesis regarding the possible location of the epileptogenic zone (EZ). A Leksell headstock was installed on the morning of surgery, following which MRI scans were obtained and combined with previous MRI results to calculate the target position of each electrode ( $x, y$, and $z$ axes; $\alpha$ angle; $\beta$ angle). Based on the calculated target positions, the electrodes were implanted using the Leksell stereotactic system. Postoperative high-resolution computed tomography (CT) scans were obtained to verify the exact location of each contact and to screen for postoperative complications. FreeSurfer (http://www.surfer.nmr.mgh.harvard.edu) was used to generate three-dimensional (3D) surface images of the brain, in order to determine the relationships of electrode position, the corresponding cortex, and surface vessels. Postoperative CT images were then co-registered with preoperative MR images using 3D Slicer (http://www.slicer.org) to confirm the actual locations of the SEEG electrodes.

The number of implanted SEEG electrodes ranged from 8 to 16 (median: 11.5) per patient, and the locations of the SEEG electrodes varied among patients.

Table 1 Demographics and clinical features of patients $(n=10)$

\begin{tabular}{|c|c|c|c|c|c|c|c|c|c|}
\hline Patient & $\begin{array}{l}\text { Age/Sex } \\
(M / F)\end{array}$ & $\begin{array}{l}\text { Age at } \\
\text { onset }(Y)\end{array}$ & MRI & $\begin{array}{l}\text { PET } \\
\text { hypometabolism }\end{array}$ & Hypothesis & Surgery & Pathology & $\begin{array}{l}\text { ILAE class/ } \\
\text { Outcome (M) }\end{array}$ & Complication \\
\hline 1 & $17 \mathrm{M}$ & 8 & Normal & Rt. F, rt. P & Rt. $P$, rt. F & Rt. PrC & FCD & $1(29)$ & None \\
\hline 2 & $6 \mathrm{M}$ & 2.5 & Lt. P PG & Lt. F, It. P & Lt. P, It. F, It. T & Lt. PrC, It. SPL & PG & $1(23)$ & None \\
\hline 3 & $19 M$ & 7.5 & Normal & Rt. $P$ & Rt. P, rt. F, rt. T & Rt. PrC, rt. PCC & FCD & $2(30)$ & None \\
\hline 4 & $20 M$ & 16 & Lt. P, It. O & Lt. $P$ & Lt. P, It. O, It. T & Lt. $\mathrm{PrC}$, It. Cu & EM & $1(35)$ & $\begin{array}{l}\text { Rt. Inf. } \\
\text { quadranopsia }\end{array}$ \\
\hline 5 & $8 M$ & 3 & Normal & Lt. T, It. P & Rt. $P$, rt. T & $\begin{array}{l}\text { Rt. PrC, rt. RSC, } \\
\text { rt. PCC }\end{array}$ & FCD & $2(34)$ & None \\
\hline 6 & $17 \mathrm{M}$ & 3 & Normal & Lt. T & Lt. P, It. O, It. T & Lt. PrC, It. Cu & FCD & $2(33)$ & $\begin{array}{l}\text { Rt. Inf. } \\
\text { quadranopsia }\end{array}$ \\
\hline 7 & $19 \mathrm{M}$ & 19 & Lt. P lesion & Normal & Lt. P, It. F & Lt. PrC, It. PCL & EM & $1(26)$ & $\begin{array}{l}\text { Transient Rt. LE } \\
\text { paresthesia }\end{array}$ \\
\hline 8 & $4 M$ & 0.5 & Normal & Bil. T & Lt.P, It. T, It. O, It, I & Lt. PrC, It. PCC & FCD & $1(18)$ & $\begin{array}{l}\text { Upper respiratory } \\
\text { infection }\end{array}$ \\
\hline 9 & $15 F$ & 1.5 & $\begin{array}{l}\text { Bil. P and bil. } \\
\mathrm{O} \text { lesion }\end{array}$ & Lt. T & Lt. P, It. O, It. F & Lt. PrC, It. PCC, It. Cu & EM & $2(37)$ & $\begin{array}{l}\text { Rt. Inf. } \\
\text { quadranopsia }\end{array}$ \\
\hline 10 & $11 \mathrm{M}$ & 0.5 & $\begin{array}{l}\text { Lt. } P \text { and bil. } \\
\text { O lesion }\end{array}$ & Lt. T, It. P & Lt. P, It. O, It. T & $\begin{array}{l}\text { Lt. PrC, It. PCC, It. Cu, } \\
\text { It.RSC }\end{array}$ & EM & $2(37)$ & $\begin{array}{l}\text { Rt. Inf. } \\
\text { quadranopsia }\end{array}$ \\
\hline
\end{tabular}

Bil bilateral, $L t$ left, $R t$ right, Inf inferior, $F$ frontal, $T$ temporal, $P$ parietal, $O$ occipital, $I$ insula, $P r C$ precuneus, SPL superior parietal lobule, $P C C$ posterior cingulate cortex, $C U$ cuneus, $R S C$ retrosplenial cortex, $P C L$ paracentral lobule, $F C D$ focal cortical dysplasia, $P G$ pachygyria, $E M$ encephalomalacia, $L E$ lower extremity 
Table 2 Features of scalp EEG and semiology in patients $(n=10)$

\begin{tabular}{|c|c|c|c|c|c|c|c|}
\hline \multirow[t]{2}{*}{ No } & \multicolumn{2}{|l|}{ Interictal } & \multicolumn{2}{|l|}{ Ictal } & \multirow[t]{2}{*}{ Semiology sequence } & \multirow{2}{*}{$\begin{array}{l}\text { Seizure } \\
\text { number }\end{array}$} & \multirow{2}{*}{$\begin{array}{l}\text { Seizure } \\
\text { duration/frequence }\end{array}$} \\
\hline & Lateralization & Site & Lateralization & Site & & & \\
\hline 1 & NA & Central-parietal & NA & NA & Left limb tonic $\rightarrow$ hypermotor & 13 & $20-30 s ; 2-3 / d$ \\
\hline 2 & NA & $\begin{array}{l}\text { Temporal- } \\
\text { parietal-occipital }\end{array}$ & NA & NA & $\begin{array}{l}\text { Aura(indescribable discomfort) } \rightarrow \text { eyes right } \\
\text { deviation } \rightarrow \text { bilateral asymmetric tonic seizure }\end{array}$ & 6 & $90 \mathrm{~s}-150 \mathrm{~s} ; 1-2 / \mathrm{m}$ \\
\hline 3 & NA & $\begin{array}{l}\text { Temporal- } \\
\text { parietal-occipital }\end{array}$ & Rt & $\begin{array}{l}\text { Temporal- } \\
\text { parietal-occipital }\end{array}$ & $\begin{array}{l}\text { Aura(vestibular response) } \rightarrow \text { left } \\
\text { versive } \rightarrow \text { bilateral asymmetric tonic seizure } \rightarrow \text { GTCS }\end{array}$ & 3 & $2-7 \mathrm{~min} ; 2-3 / \mathrm{m}$ \\
\hline 4 & NA & NA & $\mathrm{Lt}$ & $\begin{array}{l}\text { Temporal- } \\
\text { parietal-occipital }\end{array}$ & $\begin{array}{l}\text { Aura(vestibular response) } \rightarrow \text { bilateral asymmetric } \\
\text { tonic seizure } \rightarrow \text { right versive } \rightarrow \text { GTCS }\end{array}$ & 5 & $90 s-110 s ; 1-2 / m$ \\
\hline 5 & NA & $\begin{array}{l}\text { Temporal- } \\
\text { parietal-occipital }\end{array}$ & NA & NA & $\begin{array}{l}\text { Aura(body image disturbance) } \rightarrow \text { dyleptics } \rightarrow \text { rapid } \\
\text { eyes blinking } \rightarrow \text { bilateral asymmetric tonic seizure }\end{array}$ & 3 & $150 \mathrm{~s}-5 \mathrm{~min} ; 1-2 / \mathrm{w}$ \\
\hline 6 & NA & $\begin{array}{l}\text { Temporal- } \\
\text { parietal-occipital }\end{array}$ & NA & NA & $\begin{array}{l}\text { Aura(blur vision of eyes) } \rightarrow \text { right } \\
\text { version } \rightarrow \text { bilateral asymmetric tonic seizure }\end{array}$ & 10 & $15 S-1 \mathrm{~min} ; 3-4 / \mathrm{d}$ \\
\hline 7 & Left & Parietal & NA & NA & Aura(body image disturbance) $\rightarrow$ hypermotor & 12 & $30 s ; 3-4 / d$ \\
\hline 8 & NA & NA & NA & NA & Dialeptic $\rightarrow$ bilateral asymmetric tonic seizure & 4 & $15-30 s ; 5-6 / d$ \\
\hline 9 & NA & Diffused & NA & NA & $\begin{array}{l}\text { Aura(somatosensory aura) } \rightarrow \text { bilateral asymmetric } \\
\text { tonic seizure }\end{array}$ & 5 & $1 \mathrm{~min} 2-3 / \mathrm{w}$ \\
\hline 10 & NA & Diffused & NA & NA & Right version $\rightarrow$ hypermotor $\rightarrow$ GTCS & 6 & $3 \min 3-4 / w$ \\
\hline
\end{tabular}

Signals were recorded by $5-18$ contacts per intracranial electrode. SEEG data were recorded at a sampling rate of $2000 \mathrm{~Hz}$ and band-pass filtered between $0.16 \mathrm{~Hz}$ and $600 \mathrm{~Hz}$ (Nihon Koden, Japan), or at a sampling rate of $256 \mathrm{~Hz}$ and band-pass filtered between $0.16 \mathrm{~Hz}$ and $100 \mathrm{~Hz}$ (Bio-logic, USA). SEEG electrodes were referenced to screw electrodes placed at the vertex or to white matter electrodes.

Ictal onset and propagation were retrospectively analyzed by three clinicians based on the SEEG data. Following implantation, the clinicians analyzed the semiological sequence, ictal SEEG evolution, and the underlying anatomical structures for each seizure. As the seizure evolved, we marked the time points corresponding to each symptom and the electrode contacts exhibiting fast SEEG rhythms, following which we determined the corresponding anatomical locations on MR images. Finally, we analyzed the relationship between the anatomical position of the fast rhythm and the appearance of symptoms based on seizure evolution, as well as the anatomical-electrical-clinical relationship of each seizure.

\section{Surgery and pathology}

The surgical procedure was performed with controlled respiration under general inhalation anesthesia. The extent of surgical resection was based on a review of the interictal and ictal changes, extraoperative cortical stimulation functional map, and imaging data collected, which were used to reach consensus at a multidisciplinary patient management conference. Areas of the brain targeted for resection were removed using a microneurosurgical technique. During the surgery, the earlier video EEG findings and intraoperative ECoG information were used to help to further identify the area targeted for resection, which typically included the ictal onset area and adjacent areas where frequent interictal spikes were demonstrated. Surgical specimens were fixed in $10 \%$ buffered formalin, embedded in paraffin, and then stained.

\section{Results \\ Semiological characteristics \\ Aura}

Seven of the 10 included patients experienced auras. Two patients experienced body image disturbance (Pt. 4 and 7) (i.e., a feeling that an extremity has spatial displacement), two patients experienced vestibular responses (Pt. 3 and 5), and one patient experienced a somatosensory aura (Pt. 9) (i.e., numbness in the bottom of the right foot spreading upwards toward the knee). One patient experienced a visual aura (Pt. 6) (i.e., blurred vision in both eyes), while one patient experienced a non-specific aura characterized by discomfort in the heart (Pt. 2).

\section{Motor manifestations}

Seven of the 10 included patients experienced BATS (Pt. $2,3,4,5,6,8$, and 9), while the remaining three experienced HMS (Pt. 1, 7, and 10). Patient 1 exhibited horizontal movement of the trunk and hips accompanied by stiffness in the contralateral limbs. Patient 7 exhibited trunk and hip movement accompanied by pedaling motions in the bilateral lower extremities. Patient 10 exhibited right upper limb flapping accompanied by pedaling motions in the bilateral lower extremities and exaggerated facial expressions. In addition, four patients 
exhibited continuous and vigorous bilateral conjugated eye movements towards the side contralateral to the epileptic region, which were accompanied by synchronous head movements.

\section{Interictal and ictal EEG data}

All patients underwent video-EEG monitoring. In Patient 7 , interictal epileptiform discharge occurred ipsilateral to the side of the EZ. Discharge was non-lateralized in eight patients, and one patient (Pt. 4) exhibited no interictal discharge. In six patients, interictal EEG signals were mainly localized to the temporal-parietal-occipital area. In the remaining four patients, interictal discharge was generalized or non-localized.

In two patients (Pt. 3, 4), the ictal onset occurred ipsilateral to the EZ, and the site of seizure onset was primarily localized in the temporal-parietal-occipital area. In the remaining patients, ictal EEG signals were generalized or non-localized.

\section{Anatomic-electrical-clinical correlations based on SEEG findings}

Two patterns of anatomic-electrical-clinical correlations were observed. The first pattern was characterized by BATS activity with ictal spread to the supplementary motor area (SMA), paracentral lobule (PCL), postcentral gyrus (PoCG), or precentral gyrus (PrCG) of the ipsilateral hemisphere. Seven of the ten included patients exhibited BATS (Fig. 1a). However, due to limitations in the number and scope of the electrodes, data from only three patients were used to explore the frontoparietal circuits.

The ictal SEEG trace of Patient 2 revealed that seizure onset was characterized by the appearance of fast, low-voltage discharge (gamma band) in the precuneus (mesial contacts of electrode $\mathrm{C} 1-3$ ). After $5 \mathrm{~s}$, an indescribable aura appeared. Approximately $20 \mathrm{~s}$ later, seizure activity spread to the PCC (mesial contacts of electrode D1-3), intraparietal sulcus (IPS) (middle contacts of electrode D8-10), and PoCG (lateral contacts of electrode E12-16). At this time, rightward deviation of the eyes was observed. A BATS was observed only when ictal activity had propagated to the PCL (mesial contacts of electrode J1-3), PrCG (lateral contacts of electrode K10-14), and SMA (mesial contacts of electrode L1-2) (Fig. 2).

The ictal SEEG recording of Patient 9 revealed that seizure onset occurred in the precuneus (mesial contacts of electrode D1-3). Two seconds later, a somatosensory aura was observed. BATS activity appeared once the seizure had spread to the SMA (mesial contacts of electrode F1-2), PrCG (lateral contacts of electrode F8-12), PCL (mesial contacts of electrode K1-3), and PoCG (lateral contacts of electrode K10-14) (Fig. 3).

The ictal SEEG recording of Patient 3 revealed that seizure onset occurred within a relatively focal region of the
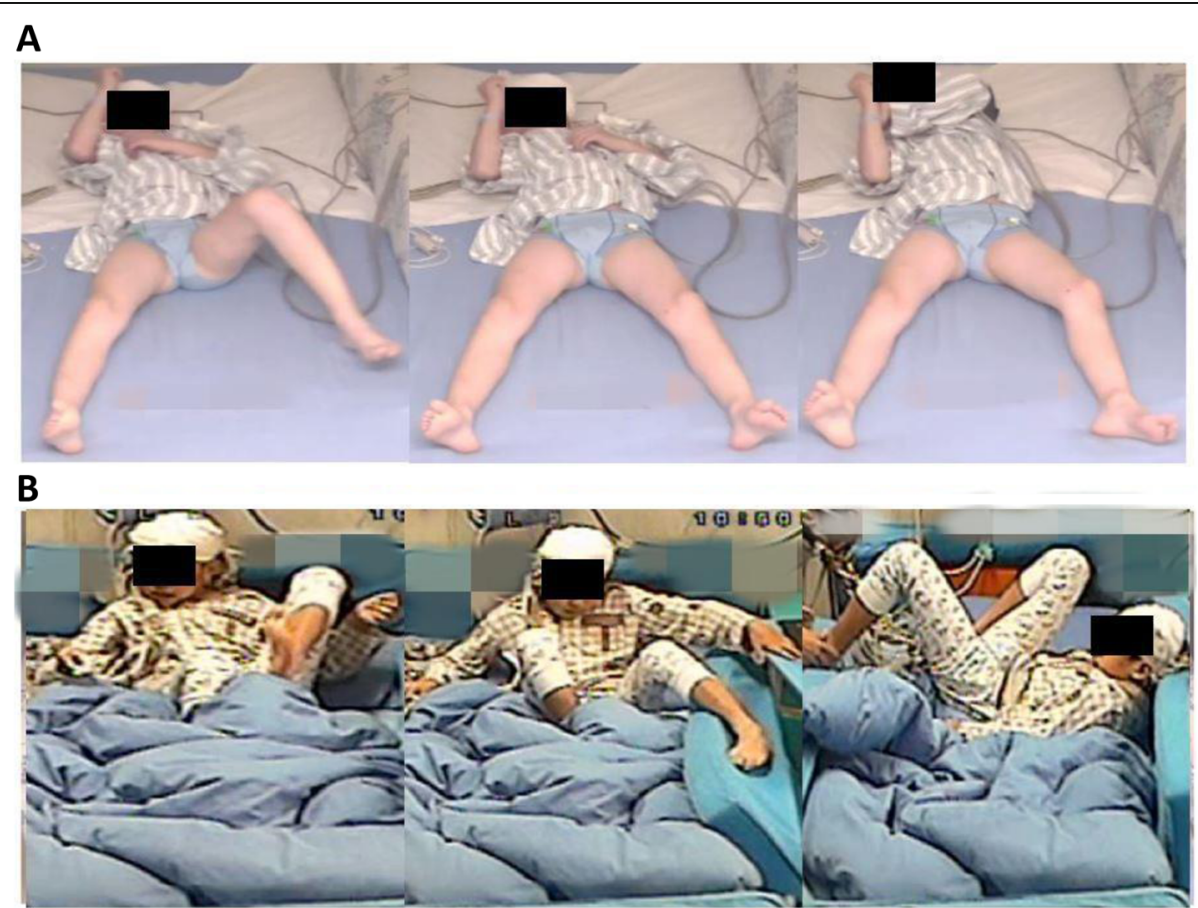

Fig. 1 Seizure samples. Video samples of the BATS of patient 2 (a) and the HMS of patient 10 (b). Signed consent forms authorizing publication have been obtained for all identifiable patients 

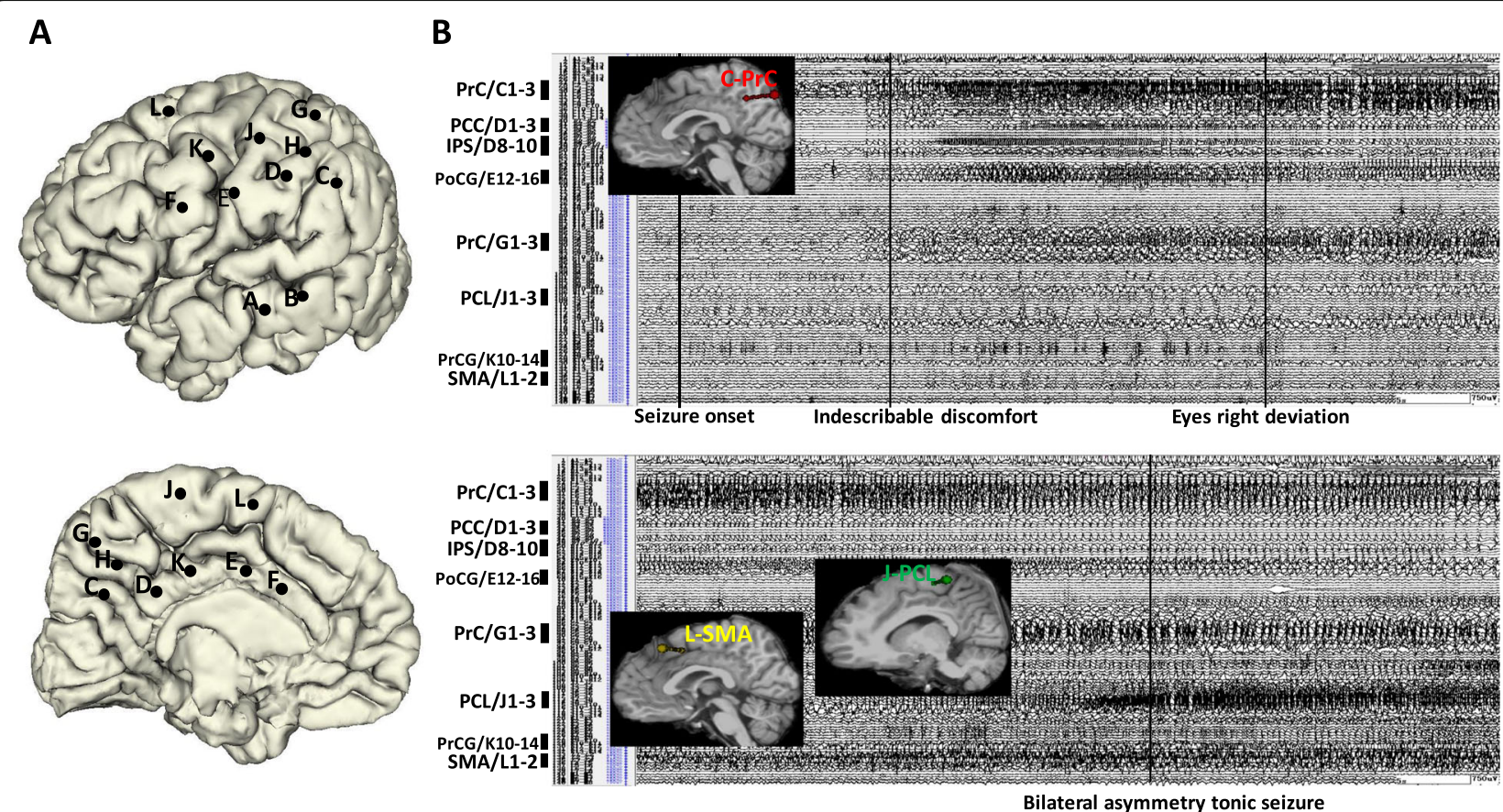

Fig. 2 a SEEG electrode implantation on lateral and medial view of three-dimensional (3D) brain of Patient 2. b Ictal SEEG trace and two-dimension (2D) T1-weighted sagittal images with 3D electrodes showing the key target points. It shows that the seizure onset was recorded from precuneus (PrC) (medial contacts of electrode (1-3) with no clinical sign being observed. When the ictal activity spread to PCL (medial contacts of electrode J1-3), PrCG (lateral contacts of electrode K10-14), and SMA (medial contacts of electrode L1-2), the clinical sign of bilateral asymmetry tonic seizure appeared
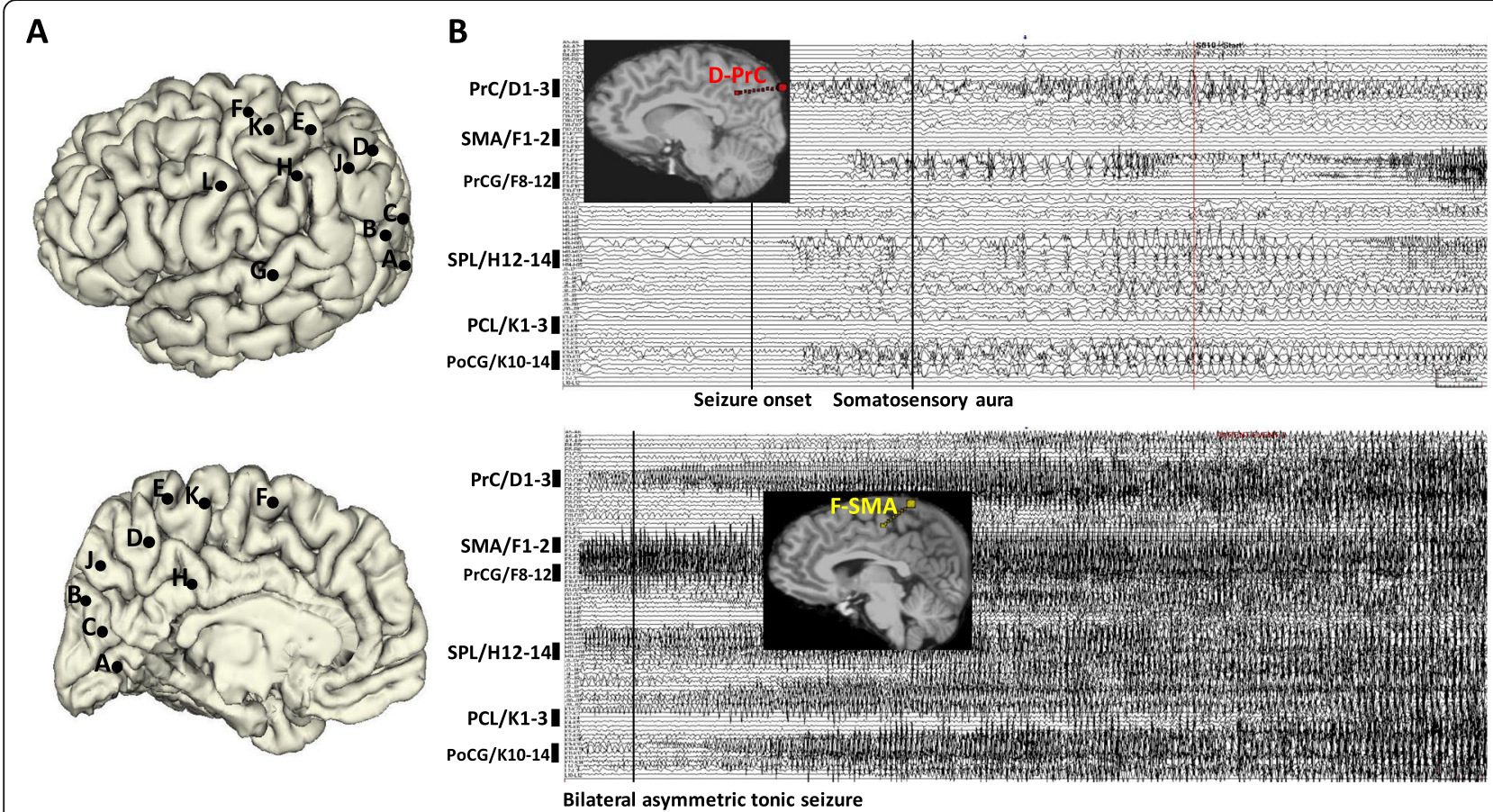

Fig. 3 a SEEG electrode implantation on lateral and medial view 3D brain of Patient 9. b Ictal SEEG trace and 2D T1-weighted sagittal images with 3D electrodes showing the key target points. It shows that the seizure onset was recorded from $\operatorname{PrC}$ (medial contacts of electrode D1-3) with no clinical sign being observed. When the seizure spreads to SMA (medial contacts of electrode F1-2), PrCG (lateral contacts of electrode F8-12), PCL (medial contacts of electrode K1-3), and PoCG (lateral contacts of electrode K10-14), the semiology of bilateral asymmetry tonic seizure appeared 
precuneus (middle contacts of electrode C4-7 and mesial contacts of electrode E1-3). Ten seconds later, seizure activity had spread to the PCC (mesial contacts of electrode J1-3) and IPS (middle contacts of electrode G4-6). A BATS was observed only once seizure activity had spread to the PoCG (lateral contacts of electrode H11-14) and SMA (medial contacts of electrode L1-3) (Fig. 4).

The second pattern was characterized by HMS activity with ictal spread to the PCC and MCC of the ipsilateral hemisphere, which was observed in three patients (Fig. 1b). However, due to electrode limitations, data from only two patients were used to investigate the frontoparietal circuits. The ictal SEEG trace of Patient 7 revealed that seizure onset occurred within the precuneus (medial contacts of electrode G1-3 and H1-3), in the absence of clinical signs. Hypermotor signs were observed once seizure activity had spread to the MCC (medial contacts of electrode C1-3), PCC (medial contacts of electrode F1-3), and PoCG (lateral contacts of electrode D8-12) (Fig. 5).

The ictal SEEG trace of Patient 1 revealed that seizure onset was characterized by a transition from preictal rhythmic spiking to fast discharge (gamma band) in the precuneus (medial contacts of electrode $\mathrm{C} 1-3$ and electrode D1-3), which occurred over the course of approximately $6 \mathrm{~s}$, in the absence of clinical signs. Hypermotor signs were observed only once seizure activity had spread to the MCC (medial contacts of electrode F2-5) and PCC (medial contacts of electrode G3-5) (Fig. 6).

\section{Surgical complications}

Surgical complications were observed in six patients. Four (Pt. 4, 6, 9, and 10) showed right inferior quadranopsia following resection, which was considered a complication of resection of the precuneus and cuneus. One (Pt. 7) had a transient contralateral lower extremity paresthesia, which was considered a result of postoperative edema causing transient damage to the paracentral lobule, and the symptom resolved 2 weeks later. One (Pt. 8) had upper respiratory infection on the third day after operation. This may be related to the patient's young age and weak resistance; the patient returned to normal after appropriate anti-inflammatory treatment.

\section{Discussion}

In the present study, we analyzed semiological characteristics and EEG/SEEG data in order to identify anatomicelectrical-clinical relationships in 10 patients with precuneal epilepsy. Previous studies have revealed that precuneal epilepsy is associated with several types of premonitory auras [1]. In one such study, visual auras were reported in three patients (50\%), vestibular responses in two patients (33\%), and sensations of falling or movement in one patient [10]. Previous studies have

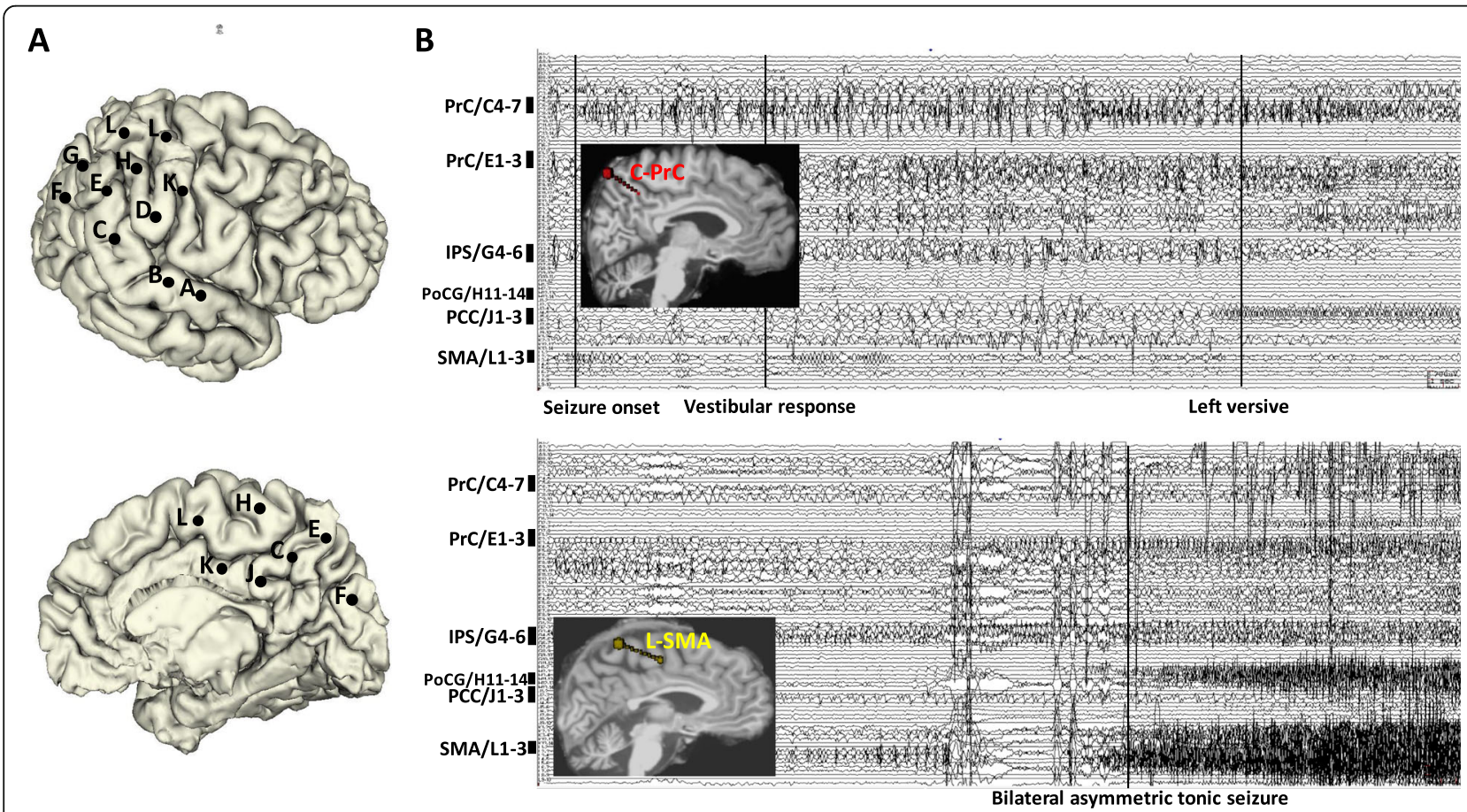

Fig. 4 a SEEG electrode implantation on lateral and medial view of 3D brain of Patient 3. b lctal SEEG trace and 2D T1-weighted sagittal images with 3D electrodes showing the key target points. It shows that the seizure onset was recorded from a relatively focal region of $\operatorname{PrC}$ (middle contacts of electrode C4-7 and mesial contacts of electrode E1-3). It is only when the seizure spreads to PoCG (lateral contacts of electrode H1 1-14) and SMA (medial contacts of electrode L1-3), that the semiology of BATS appears 
A
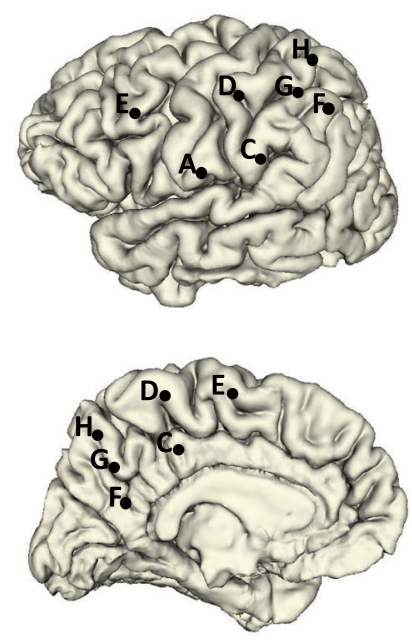

B

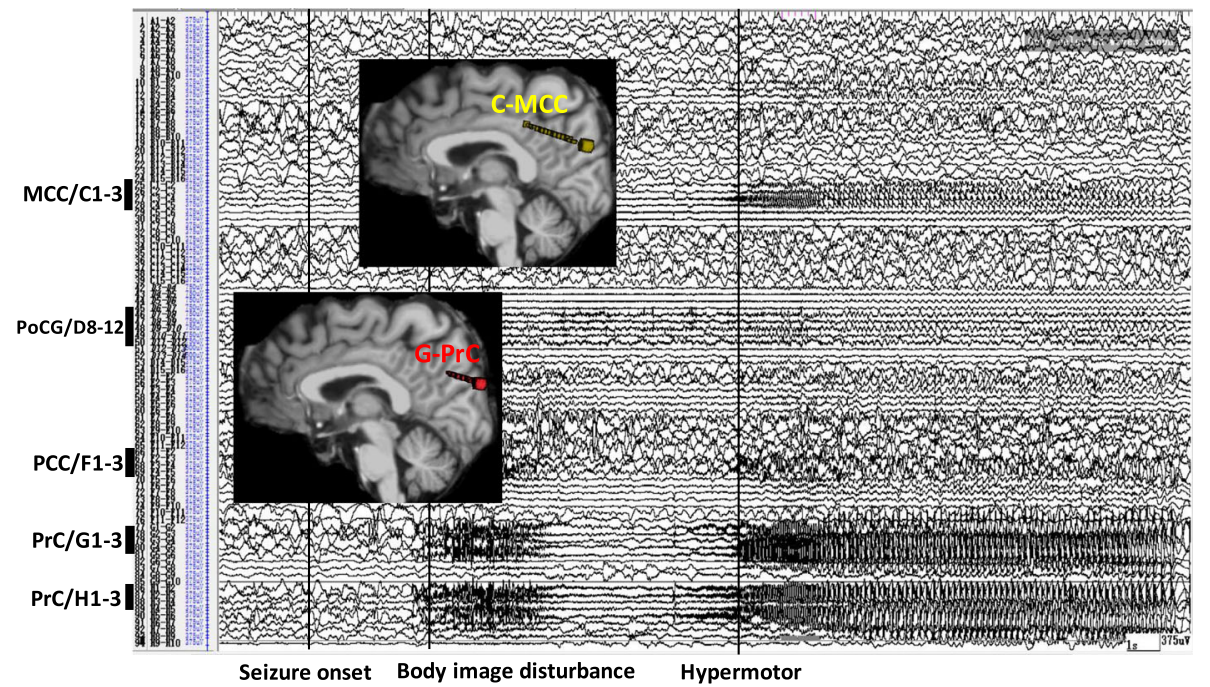

Fig. 5 a SEEG electrode implantation on lateral and medial view of 3D brain of Patient 7. b lctal SEEG trace and 2D T1-weighted sagittal images with 3D electrodes showing the key target points. It showed that seizure onset was recorded from PrC (medial contacts of electrode G1-3 and electrode $\mathrm{H1}$-3) with no clinical sign being observed. When the seizure spreads to MCC (medial contacts of electrode C1-3), PCC (medial contacts of electrode F1-3), and PoCG (lateral contacts of electrode D8-12), the semiology of hypermotor appeared

demonstrated that stimulation of the anterior portion of the precuneus results in body image disturbance, while stimulation of the posterior portion results in visuomotor illusions [21, 22]. Additional studies have reported that stimulation of the precuneus evokes vestibular responses [23]. Our findings are mostly consistent with these previous studies, although body image disturbance occurred more frequently in our patient group, perhaps because most patients exhibited seizure activity in the anterior precuneus.

We observed two major patterns of activity in patients of the present study: BATS and HMS. BATS is often associated with seizure activity in the mesial parietal region [24], similar to patterns observed in patients with mesial frontal lobe epilepsy. However, seizures originating from the precuneus are typically briefer than those

\section{A}
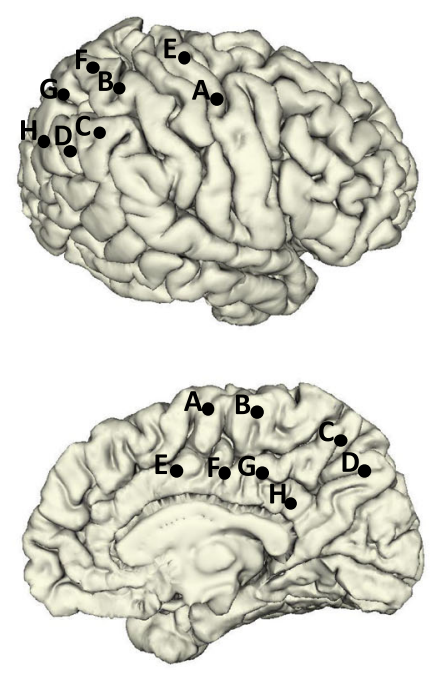

B

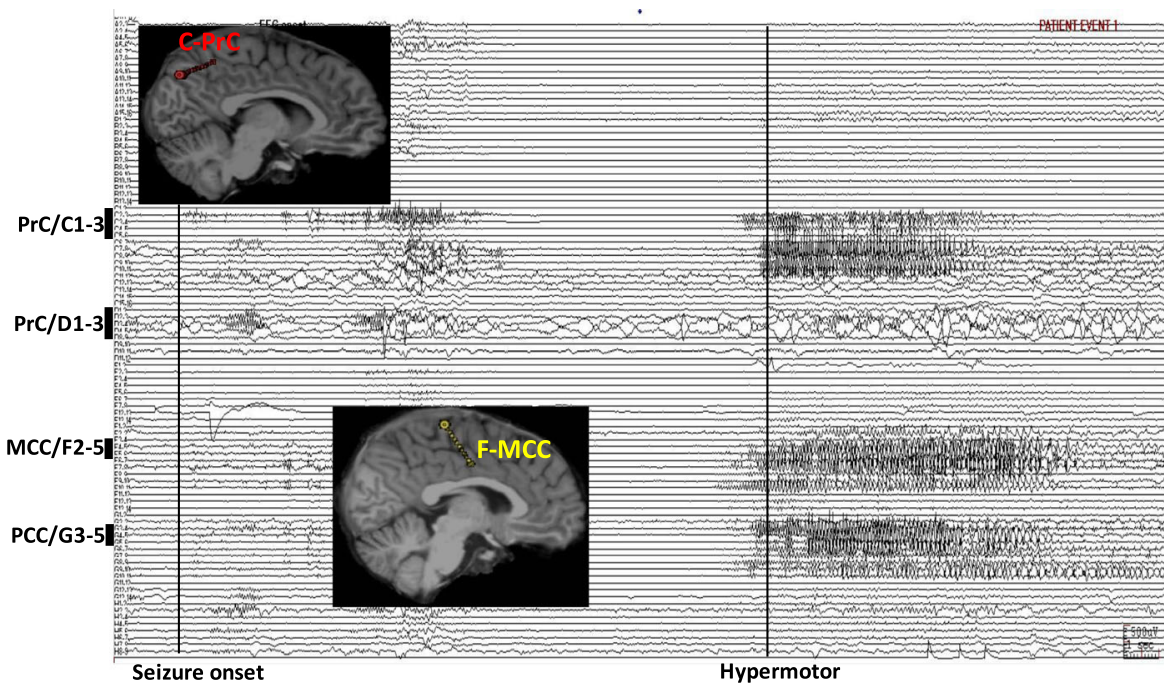

Fig. 6 a SEEG electrode implantation on lateral and medial view of 3D brain of Patient 3. b Ictal SEEG trace and 2D T1-weighted sagittal images with 3D electrodes showing the key target points. It shows that seizure onset was recorded from PrC (medial contacts of electrode C1-3 and electrode D1-3). Only when the seizure spread to MCC (medial contacts of electrode F2-5) and PCC (medial contacts of electrode G3-5), the semiology of hypermotor emerged 
with an SMA onset, and patients with precuneal seizures are typically quicker to regain awareness [25]. These features were also observed in our patients who experienced BATS.

Some studies have reported that seizures originating from the lateral and mesial parietal regions may manifest as hypermotor activity [26]. Such hypermotor activity was also observed in some patients of the present study. However, HMS typically has a frontal lobe onset and occur in $15-27 \%$ of patients with frontal lobe epilepsy, in which seizures primarily rise from the orbitofrontal or mesial frontal cortex [27-29]. In such cases, it is difficult to distinguish seizures arising from the parietal lobe from those arising from the frontal lobe. However, some studies have indicated that the type of aura and the delay between seizure onset and hypermotor activity can be used to make this distinction [26]. As previously mentioned, precuneal HMS is often preceded by unique auras (e.g., body image disturbance and vestibular responses). In addition, patients with frontal lobe seizures almost always experience hypermotor activity at seizure onset or during the first third of the seizure [30]. However, in patients with precuneal seizures, there is usually a substantial delay between seizure onset and the appearance of hypermotor activity, which may represent the time required for the seizure to propagate from the precuneus to the frontal lobe or to subcortical structures [31, 32].

In precuneal epilepsy, the interictal EEG provides little clue to the lateralization and localization of seizure activity [9], as discharge is prone to spread to other cerebral lobes and induce an error in localization. The widespread connectivity between the precuneus and other cerebral regions may represent the underlying cause of errors in localization. Hence, it is difficult to distinguish precuneal from non-precuneal seizures via scalp EEG, particularly those arising from the mesial frontal lobe. SEEG represents a unique method for identifying and characterizing the underlying physiologic mechanisms of precuneal seizures.

In SEEG methodology, the EZ is defined as the site of origin for epileptic seizures [33]. Therefore, we focused our SEEG analyses mainly on the identification of the brain regions in which specific ictal patterns developed during seizures $[34,35]$. The region associated with the primary organization of ictal discharge and subsequent propagation is correlated with the anatomical positions of the electrodes that display maximal abnormal activity, and with the evolution of clinical seizure signs. At present, however, the identification of the EZ is based on the ability of experienced clinical neurophysiologists to identify the relevant anatomic-electrical-clinical correlations and SEEG patterns.

In the present study, we analyzed the ictal SEEG of five patients in whom the relevant electrodes involved the frontoparietal network. In three cases, BATS was observed only once the ictal activity had spread to the SMA, PCL, PrCG, or PoCG. Our results indicated that abnormal ictal activity is easily propagated from the precuneus to these regions, suggesting that the precuneus is functionally connected to the SMA and other central areas. Some previous studies have reported that the medial aspect of the posterior parietal lobe is connected to the SMA and premotor areas $[4,36]$. Therefore, seizures occurring within the medial side of the parietal lobe may spread to the SMA, causing bilateral asymmetric tonic manifestations [24].

In two patients of the present study, HMS was observed only when ictal activity had spread to the PCC and MCC. Some studies have reported that the middle cingulate gyrus receives afferent connections from the medial surface of the parietal lobe, particularly the precuneus. Such connections provide information regarding noxious stimulation in the body, directing the motor area of the cingulate gyrus to initiate evasive actions/behaviors. Thus, seizure activity originating from the precuneus may induce hypermotor movements [37]. In one case series, two patients with electrodes implanted in the motor aspect of the MCC exhibited fast discharge in this region during hypermotor movements [26]. Thus, hypermotor activity associated with precuneal seizures may be due to the ease with which abnormal ictal activity propagates from the precuneus to the PCC and MCC. Taken together, the accumulated evidence suggests that the precuneus is functionally connected with the PCC and MCC.

The present study possesses several limitations of note. First, the study was limited by the number and coverage of the implanted electrodes. The spatial limitations of recording may have caused difficulties in identifying all possible pathways of seizure propagation. The study was also limited by the small number of included cases and its retrospective design. Nonetheless, our study provides valuable evidence regarding the electroclinical characteristics of precuneal epilepsy, as well as the possible mechanisms underlying variations in semiology based on SEEG findings within frontoparietal circuits. Such findings may represent clinical indicators of precuneal epilepsy. Future studies should investigate further subdivisions of the precuneus using a greater number of electrodes in order to provide a more complete characterization of precuneal epilepsy.

\section{Conclusion}

The clinical characteristics of precuneal epilepsy are complex and various. Aura type (e.g., body image disturbance and vestibular response), BATS, and HMS are the main indicators of precuneal epilepsy. Scalp EEG is of little use when attempting to localize precuneal 
seizures. Analysis of high-quality SEEG data can help to identify the relevant anatomic-electrical-clinical correlations. Our findings indicate that the clinical characteristics of precuneal epilepsy are different among patients, and that the final electro-clinical phenotype depends on the pattern of seizure spread.

\section{Abbreviations}

2D: Two-dimensional; 3D: Three-dimensional; BATS: Bilateral asymmetric tonic seizure; CT: Computed tomography; EEG: Electroencephalography; EZ: Epileptogenic zone; HMS: Hypermotor seizure; IPS: Intraparietal sulcus; MCC: Middle cingulate cortex; MRI: Magnetic resonance imaging: PCC: Posterior cingulate cortex; PCL: Paracentral lobule; PET: Positron emission tomography; PoCG: Postcentral gyrus; PrC: Precuneus; PrCG: Precentral gyrus; SEEG: Stereoeletroencephalography; SMA: Supplementary motor area; SPL: Superior parietal lobule

\section{Funding}

This work supported by National Natural Science Foundation of China (81571267) and the capital health research and development of special (2016-2-2013)

\section{Availability of data and materials}

The datasets during and analyzed during the current study are available from the first and corresponding authors on reasonable request.

\section{Authors' contributions}

YY contributed to the data acquisition and analysis of the manuscript. WS and GZ contributed to the data acquisition, analysis and redaction of the manuscript, and also the interpretation of the data. WZ and HW contributed to the data acquisition. TQ contributed to redaction of the manuscript. All authors read and approved the final manuscript.

\section{Ethics approval and consent to participate}

The study was performed under a protocol approved by the ethic committee of Xuanwu Hospital of Capital Medical University, Beijing, China. The ethic committee of the hospital granted me permission to access the medical records for the purpose of this study. The study participants and their caregivers agreed to participate in this study, and all provided written informed consent. The consent obtained covered the publication of personal and potentially identifying information such as age and gender.

\section{Consent for publication}

Informed consents to publish were obtained from the patients with individual data involved in this article.

\section{Competing interests}

None of the authors has any conflict of interest to disclose. We confirm that we have read the Journal's position on issues involved in ethical publication and affirm that this report is consistent with those guidelines.

\section{Publisher's Note}

Springer Nature remains neutral with regard to jurisdictional claims in published maps and institutional affiliations.

\section{Author details}

'Department of Neurology, Xuan Wu Hospital, Capital Medical University, No 45, Changchun Street, Xicheng District, Beijing 100053, China. ${ }^{2}$ Department of Neurosurgery, Xuan Wu Hospital, Capital Medical University, No 45, Changchun Street, Xicheng District, Beijing 100053, China. ${ }^{3}$ Epilepsy Center, Yuquan hospital, Tsinghua University, Beijing 100049, China. ${ }^{4}$ Department of Radiology, Beijing Key Lab of magnetic resonance imaging (MRI) and Brain Informatics, Xuan Wu Hospital, Capital Medical University, Beijing 100053, China.
Received: 2 November 2017 Accepted: 6 August 2018

Published online: 13 August 2018

\section{References}

1. Harroud A, Boucher O, Tran TPY, Harris L, Hall J, Dubeau F, Mohamed I, Bouthillier A, Nguyen DK. Precuneal epilepsy: clinical features and surgical outcome. Epilepsy Behav. 2017;73:77-82.

2. Cavanna AE, Trimble MR. The precuneus: a review of its functional anatomy and behavioural correlates. Brain. 2006;129(Pt 3):564-83.

3. Rizzolatti G, Luppino G, Matelli M. The organization of the cortical motor system: new concepts. Electroencephalogr Clin Neurophysiol. 1998;106(4):283-96.

4. Scheperjans F, Eickhoff SB, Homke L, Mohlberg H, Hermann K, Amunts K, Zilles K. Probabilistic maps, morphometry, and variability of cytoarchitectonic areas in the human superior parietal cortex. Cerebral Cortex (New York : 1991). 2008;18(9):2141-57.

5. Caminiti R, Innocenti GM, Battaglia-Mayer A. Organization and evolution of parieto-frontal processing streams in macaque monkeys and humans. Neurosci Biobehav Rev. 2015;56:73-96.

6. Margulies DS, Vincent JL, Kelly C, Lohmann G, Uddin LQ, Biswal BB, Villringer A, Castellanos FX, Milham MP, Petrides M. Precuneus shares intrinsic functional architecture in humans and monkeys. Proc Natl Acad Sci U S A. 2009;106(47):20069-74.

7. Salanova V, Andermann F, Rasmussen T, Olivier A, Quesney LF. Parietal lobe epilepsy. Clinical manifestations and outcome in 82 patients treated surgically between 1929 and 1988. Brain. 1995;118(Pt 3):607-27.

8. Francione S, Liava A, Mai R, Nobili L, Sartori I, Tassi L, Scarpa P, Cardinale F, Castana L, Cossu M, Russo GL. Drug-resistant parietal epilepsy: polymorphic ictal semiology does not preclude good post-surgical outcome. Epileptic Disord. 2015:17(1):32-46.

9. Salanova V. Parietal lobe epilepsy. J Clin Neurophysiol. 2012;29(5):392-6.

10. Bartolomei F, Gavaret M, Hewett R, Valton L, Aubert S, Regis J, Wendling F, Chauvel P. Neural networks underlying parietal lobe seizures: a quantified study from intracerebral recordings. Epilepsy Res. 2011;93(2-3):164-76.

11. Salanova V, Andermann F, Rasmussen T, Olivier A, Quesney LF. Tumoural parietal lobe epilepsy. Clinical manifestations and outcome in 34 patients treated between 1934 and 1988. Brain. 1995;118(Pt 5):1289-304.

12. Enatsu R, Bulacio J, Nair DR, Bingaman W, Najm I, Gonzalez-Martinez J. Posterior cingulate epilepsy: clinical and neurophysiological analysis. J Neurol Neurosurg Psychiatry. 2014;85(1):44-50.

13. Foldvary N, Klem G, Hammel J, Bingaman W, Najm I, Luders $\mathrm{H}$. The localizing value of ictal EEG in focal epilepsy. Neurology. 2001;57(11):2022-8.

14. Talairach J, Bancaud J, Bonis A, Szikla G, Tournoux P. Functional stereotaxic exploration of epilepsy. Confin Neurol. 1962;22:328-31.

15. McGonigal A, Bartolomei F, Regis J, Guye M, Gavaret M, Trebuchon-Da Fonseca A, Dufour H, Figarella-Branger D, Girard N, Peragut JC, et al. Stereoelectroencephalography in presurgical assessment of MRI-negative epilepsy. Brain. 2007;130(Pt 12):3169-83.

16. Gavaret M, Trebuchon A, Bartolomei F, Marquis P, McGonigal A, Wendling F, Regis J, Badier JM, Chauvel P. Source localization of scalp-EEG interictal spikes in posterior cortex epilepsies investigated by HR-EEG and SEEG. Epilepsia. 2009;50(2):276-89.

17. Chauvel P, Kliemann F, Vignal JP, Chodkiewicz JP, Talairach J, Bancaud J. The clinical signs and symptoms of frontal lobe seizures. Phenomenology and classification. Adv Neurol. 1995:66:115-25. discussion 125-116

18. Bonini F, McGonigal A, Trebuchon A, Gavaret M, Bartolomei F, Giusiano B, Chauvel P. Frontal lobe seizures: from clinical semiology to localization. Epilepsia. 2014;55(2):264-77.

19. Wieser HG, Blume WT, Fish D, Goldensohn E, Hufnagel A, King D, Sperling MR, Luders H, Pedley TA. ILAE commission report. Proposal for a new classification of outcome with respect to epileptic seizures following epilepsy surgery. Epilepsia. 2001;42(2):282-6.

20. Luders H, Acharya J, Baumgartner C, Benbadis S, Bleasel A, Burgess R, Dinner DS, Ebner A, Foldvary N, Geller E, et al. Semiological seizure classification. Epilepsia. 1998;39(9):1006-13.

21. Richer F, Martinez M, Cohen H, Saint-Hilaire JM. Visual motion perception from stimulation of the human medial parieto-occipital cortex. Exp Brain Res. 1991;87(3):649-52.

22. Richer F, Martinez M, Robert M, Bouvier G, Saint-Hilaire JM. Stimulation of human somatosensory cortex: tactile and body displacement perceptions in medial regions. Exp Brain Res. 1993;93(1):173-6. 
23. Kahane P, Hoffmann D, Minotti L, Berthoz A. Reappraisal of the human vestibular cortex by cortical electrical stimulation study. Ann Neurol. 2003; 54(5):615-24.

24. Khan SA, Carney PW, Archer JS. Brief asymmetric tonic posturing with diffuse low-voltage fast activity in seizures arising from the mesial parietal region. Epilepsy Res. 2014;108(10):1950-4.

25. Baumgartner C, Flint R, Tuxhorn I, Van Ness PC, Kosalko J, Olbrich A, Almer G, Novak K, Luders HO. Supplementary motor area seizures: propagation pathways as studied with invasive recordings. Neurology. 1996;46(2):508-14.

26. Montavont A, Kahane P, Catenoix H, Ostrowsky-Coste K, Isnard J, Guenot M, Rheims S, Ryvlin P. Hypermotor seizures in lateral and mesial parietal epilepsy. Epilepsy Behav. 2013;28(3):408-12.

27. Jobst BC, Siegel AM, Thadani VM, Roberts DW, Rhodes HC, Williamson PD. Intractable seizures of frontal lobe origin: clinical characteristics, localizing signs, and results of surgery. Epilepsia. 2000;41(9):1139-52.

28. Rheims S, Ryvlin P, Scherer C, Minotti L, Hoffmann D, Guenot M, Mauguiere F, Benabid AL, Kahane P. Analysis of clinical patterns and underlying epileptogenic zones of hypermotor seizures. Epilepsia. 2008;49(12):2030-40.

29. Gibbs SA, Figorilli M, Casaceli G, Proserpio P, Nobili, L. Sleep related hypermotor seizures with a right parietal onset. J Clin Sleep Med. 2015;11(8): 953-5.

30. Kotagal P, Arunkumar G, Hammel J, Mascha E. Complex partial seizures of frontal lobe onset statistical analysis of ictal semiology. Seizure. 2003; 12(5):268-81.

31. Ryvlin $P$, Minotti L, Demarquay $G$, Hirsch E, Arzimanoglou A, Hoffman D, Guenot M, Picard F, Rheims S, Kahane P. Nocturnal hypermotor seizures, suggesting frontal lobe epilepsy, can originate in the insula. Epilepsia. 2006:47(4):755-65.

32. Dobesberger J, Ortler $\mathrm{M}$, Unterberger I, Walser $\mathrm{G}$, Falkenstetter $\mathrm{T}$, Bodner T, Benke T, Bale R, Fiegele T, Donnemiller E, et al. Successful surgical treatment of insular epilepsy with nocturnal hypermotor seizures. Epilepsia. 2008;49(1):159-62.

33. Munari C, Bancaud J. The role of stereo-electro-encephalography (SEEG) in the evaluation of partial epileptic patients. London: Butterworths; 1987. p. 267-306.

34. Bancaud J, Angelergues R, Bernouilli C, Bonis A, Bordas-Ferrer M, Bresson M, Buser P, Covello L, Morel P, Szikla G, et al. Functional stereotaxic exploration (SEEG) of epilepsy. Electroencephalogr Clin Neurophysiol. 1970;28(1):85-6.

35. Engel J Jr. Epilepsy surgery. Curr Opin Neurol. 1994;7(2):140-7.

36. Scheperjans F, Hermann K, Eickhoff SB, Amunts K, Schleicher A, Zilles K. Observer-independent cytoarchitectonic mapping of the human superior parietal cortex. Cereb Cortex (New York: 1991). 2008;18(4):846-67.

37. Vogt BA. Pain and emotion interactions in subregions of the cingulate gyrus. Nat Rev Neurosci. 2005;6(7):533-44.

Ready to submit your research? Choose BMC and benefit from:

- fast, convenient online submission

- thorough peer review by experienced researchers in your field

- rapid publication on acceptance

- support for research data, including large and complex data types

- gold Open Access which fosters wider collaboration and increased citations

- maximum visibility for your research: over $100 \mathrm{M}$ website views per year

At BMC, research is always in progress.

Learn more biomedcentral.com/submissions 